\title{
Production of cellulolytic and xylanolytic enzymes during growth of the anaerobic fungus Piromyces sp. on different substrates
}

\author{
Marcel J. Teunissen, ${ }^{1 *}$ Gregor V. M. De Kort, ${ }^{1}$ Hudb J. M. Op den Camp ${ }^{1}$ and \\ JOS H. J. HUIS IN 'T VELD' \\ ${ }^{1}$ Department of Microbiology, Faculty of Science, University of Nijmegen, Toernooiveld, NL-6525 ED Nijmegen, \\ The Netherlands \\ ${ }^{2}$ Department of Biotechnology, TNO Food and Nutrition Research, Utrechtseweg 48, NL-3704 HE Zeist, \\ The Netherlands
}

(Received 18 February 1992; revised 2 April 1992; accepted 8 April 1992)

\begin{abstract}
Piromyces sp. strain E2, an anaerobic fungus isolated from an Indian elephant (hindgut fermenter) was tested for its ability to ferment a range of substrates. The fungus was able to use bagasse, cellobiose, cellulose, fructose, glucose, lactose, mannose, starch, wheat bran, wheat straw, xylan and xylose. Formate and acetate were the main fermentation products after growth on these substrates. The amount of carbon found in the fermentation products of cultures, in which substrate digestion was complete averaged $88.5 \mathrm{mM}$, or $59 \%$ of the carbon offered as substrate. No growth was observed on other substrates tested. Lactose, starch, cellobiose and filter paper cellulose were good inducers of cellulolytic and xylanolytic enzymes. Cellulolytic and xylanolytic enzymes were produced constitutively by Piromyces strain E2, although enzyme activities were generally lower after growth on glucose and other soluble sugars. Complex substrates (bagasse, wheat bran, and wheat straw) were good inducers for xylanolytic enzymes but not for cellulolytic enzymes. The extracellular protein banding pattern after SDS-PAGE was therefore only slightly affected by the growth substrate. Identical $\beta$-glucosidase and endoglucanase activity patterns were found after growth on different substrates. This indicated that differences in enzyme activities were not the result of secretion of different sets of isoenzymes although it remains possible that the relative amount of each isoenzym. produced is influenced by the growth substrate.
\end{abstract}

\section{Introduction}

Anaerobic fungi inhabiting alimentary tracts of ruminant as well as non-ruminant herbivorous mammals have an important role in the digestion of cellulose and xylan present in plant cell walls (Bauchop \& Mountfort, 1981; Orpin, 1983/1984; Lowe et al., 1987b). These zoospore-forming fungi have been assigned to the following genera: Caecomyces, Neocallimastix and Piromyces (Gold et al., 1988; Orpin, 1988), which have monocentric growth patterns, and Anaeromyces (Breton et al., 1990), Orpinomyces (Barr et al., 1989) and Ruminomyces (Ho et al., 1990) which have polycentric growth patterns. Anaerobic fungi have been shown to produce extracellular cellulolytic enzymes that degrade crystalline cellulose. Furthermore, comparative study

\footnotetext{
* Author for correspondence. Tel. 80 652316; fax 80553450 .
}

has shown that extracellular cellulase of Neocallimastix patriciarum is more active against crystalline cellulose than the cellulase of the aerobic fungus Trichoderma reesei (Wood et al., 1986), although the latter is considered as the cellulolytic fungus most suitable for possible industrial use in the conversion of cellulose to glucose.

From the point of view of economical cellulase and xylanase production, it is desirable to use inexpensive materials. Lignocellulosic biomasses, like rice straw and bagasse, have been shown to be of value for production of cellulolytic and xylanolytic enzymes by aerobic fungi (Kawamori et al., 1986). Anaerobic rumen fungi are able to ferment a range of carbohydrates (Lowe et al., 1987a; Phillips \& Gordon, 1988). The rumen fungi Neocallimastix patriciarum, Piromyces communis and a Piromyces sp. produce a range of polysaccharide-degrading enzymes and glycoside hydrolase enzymes during growth on 
several carbohydrates (Williams \& Orpin, 1987a, b). No information is given in literature with respect to these characteristics for anaerobic fungi isolated from nonruminants.

Piromyces sp. strain E2, isolated from an Indian elephant (a non-ruminant), produces higher amounts of cellulolytic enzymes than Neocallimastix patriciarum and Neocallimastix sp. (strain N1) when grown on filter paper cellulose (Teunissen et al., 1991b). This paper describes the ability of Piromyces strain E2 to ferment a range of carbohydrates. The influence of different growth substrates on induction or repression of cellulolytic and xylanolytic enzyme synthesis was studied. The extracellular proteins and enzymes with $\beta$-glucosidase and endoglucanase activity were separated by SDS-PAGE and visualized by subsequent (activity) staining.

\section{Methods}

Organisms and growth conditions. Piromyces strain E2 was isolated from an Indian elephant and was grown at $39^{\circ} \mathrm{C}$ in defined medium M2 (Teunissen et al., $1991 a, b$ ). Stock cultures of anaerobic fungi were maintained on $0 \cdot 1 \mathrm{~g}$ milled wheat straw in $19 \mathrm{ml}$ medium M2. Cultures were inoculated with $1 \mathrm{ml}$ culture fluid (containing zoospores), and subcultured every 3-4 d (Teunissen et al., 1991a).

Carbohydrate utilization. Mono-, oligo- and polysaccharides were tested as growth substrates in quadruplicate. Cellobiose, fructose and oat spelt xylan were purchased from Sigma; arabinose, galactose, D-glucose, inulin, lactose, mannose, raffinose, ribose, soluble starch, sucrose and D-xylose were obtained from Merck and Whatman filter paper (no. 1) was used. Tests for carbohydrate utilization were conducted in medium M2 containing $150 \mathrm{mM}$ fermentable carbon ( $30 \mathrm{mM}-\mathrm{C}_{5}$-sugar, $25 \mathrm{mM}^{-\mathrm{C}_{6}}$-sugar, etc.). Stock solutions of soluble carbohydrates (20-times concentrated) were sterilized separately in sealed bottles (butyl rubber septa, crimp seals; Rubber BV) under $\mathrm{N}_{2} / \mathrm{CO}_{2}(80: 20, \mathrm{v} / \mathrm{v})$ at $115^{\circ} \mathrm{C}$ for $20 \mathrm{~min}$. Sterile carbohydrate solutions were injected into the medium. Polysaccharides were included in the medium before sterilization since no caramelization was observed. Bagasse, wheat bran, and wheat straw $\left(4.6 \mathrm{~g} \mathrm{l}^{-1}\right)$ were included in the medium before sterilization. Fermentable substrate was estimated after allowance for lignin and ash as determined by the proximate method of Goering \& van Soest (1970). The fermentable amounts of bagasse, wheat bran, and wheat straw were $3.9,4.0$ and $4 \cdot 0 \mathrm{~g}^{-1}$ respectively. Inocula $(5 \%, \mathrm{v} / \mathrm{v})$ for experimental cultures were prepared by subculturing the fungus twice, at $3 \mathrm{~d}$ intervals, on the substrate to be tested.

Sample collection and treatment. Growth of the fungus was monitored by the production of hydrogen. After hydrogen production ceased four parallel cultures were harvested by filtration over Whatman glass-fibre filters (grade C). Samples $(1 \mathrm{ml})$ of the culture filtrate were stored at $-20^{\circ} \mathrm{C}$ until used for analysis of water-soluble fermentation products and determination of enzyme activities. The remaining culture filtrates were combined for SDS-PAGE and one aliquot $(2 \mathrm{ml})$ was dialysed against $25 \mathrm{mM}$-MES buffer (pH 6.5, $24 \mathrm{~h}, 4^{\circ} \mathrm{C}$ ), and another $(5.5 \mathrm{ml})$ was concentrated by ammonium sulphate precipitation $(85 \%$ saturation, $18 \mathrm{~h}, 4^{\circ} \mathrm{C}$ ). The precipitated protein was collected by centrifugation $\left(20000 \times \mathrm{g}, 45 \mathrm{~min}, 4^{\circ} \mathrm{C}\right)$, dissolved in $0.5 \mathrm{ml} 25 \mathrm{~mm}$-MES buffer (pH $\left.6.5,4^{\circ} \mathrm{C}\right)$ and dialyzed against the same buffer $\left(18 \mathrm{~h}, 4^{\circ} \mathrm{C}\right)$.
Fermentation product analysis. Formic acid was determined by the colorimetric method of Sleat \& Mah (1984). Acetate, ethanol and lactate were determined by (GLC) using the method of Teunissen et al. (1989). Hydrogen in $0.5 \mathrm{ml}$ of head space gas samples, was quantified with a Hewlett Packard 5890A gas chromatograph fitted with a thermal conductivity detector and a column packed with 80-100 mesh Porapack Q (Supelco). Ethane was used as internal standard and hydrogen as external standard.

Residual sugar analysis. Soluble (reducing) sugars were determined with dinitrosalicylic acid (DNS) reagent (Miller, 1959); the ratio of sample to DNS was $1: 2$ and after boiling for $15 \mathrm{~min}$ the $A_{575}$ was measured against glucose, galactose or xylose standards treated in the same way. Residual polysaccharides were hydrolysed with $67 \%(\mathrm{v} / \mathrm{v})$ $\mathrm{H}_{2} \mathrm{SO}_{4}$ for $1 \mathrm{~h}$ and soluble sugars were determined after appropriate dilution.

Enzyme assays. Enzyme assays with culture fluid were performed in duplicate at optimum $\mathrm{pH}$ and temperature. All enzyme reactions were linear over the period of the assays. Enzyme and substrate controls were included in all assays. Endoglucanase, $\beta$-glucosidase and xylanase were assayed in $0 \cdot 1 \mathrm{M}$-citrate-phosphate buffer $(\mathrm{pH} 6 \cdot 0)$ at $50{ }^{\circ} \mathrm{C}$ with low viscosity sodium carboxymethylcellulose, $p$-nitrophenyl- $\beta$-D-glucopyranoside (PNPG) and washed oat spelt xylan, respectively, as described by Teunissen et al. (1991 b). Exoglucanase was assayed in the same buffer at $40^{\circ} \mathrm{C}$ with Avicel (microcrystalline cellulose; type PH105; Serva), as substrate (Teunissen et al., 1991 b). Units of activity (IU) are defined as $\mu$ mol product released per min.

Electrophoresis. SDS-PAGE was performed in $10 \%(\mathrm{w} / \mathrm{v})$ polyacrylamide slab gels in the presence of SDS $(0 \cdot 1 \%, w / v)$ as described by Laemmli (1970). Enzyme samples were denatured in $5 \%(w / v)$ SDS by incubation for $5 \mathrm{~min}$ at $100^{\circ} \mathrm{C}$ (for gels stained for protein) or for $18 \mathrm{~h}$ at $20^{\circ} \mathrm{C}$ (for zymograms). Both the low and high denaturation temperature conditions resulted in a complete dissociation of proteins (unpublished data). Molecular size standards were the Low Molecular Weight Calibration Kit, High Molecular Weight SDS Kit (Pharmacia Fine Chemicals) and the High Molecular Weight Standard Mixture SDS-6H (Sigma). Both high and low molecular mass standards were applied to each gel. Electrophoresis was conducted at $15^{\circ} \mathrm{C}$ with a constant current of $40 \mathrm{~mA}$ until the tracking dye reached the bottom of the slab gels. Protein bands were detected by staining with Coomassie brilliant blue G-250 (Serva). The amount of protein applied to the gels varied from 5 to $50 \mu \mathrm{g}$.

Enzyme activities in gels were detected by a modification (unpublished data) of the method described by Schwartz et al. (1987). The CMC endoglucanase substrate $(0 \cdot 2 \%, w / v)$ was incorporated into the separation gel before addition of ammonium persulphate and polymerization. After electrophoresis the gels were washed three times in $150 \mathrm{ml} 0 \cdot 1 \mathrm{M}$-phosphate-citrate buffer $\left(\mathrm{pH} \mathrm{6.0)}\right.$ ) for $30 \mathrm{~min}$ at $4{ }^{\circ} \mathrm{C}$, and were then submerged and incubated in the same buffer for $2.5 \mathrm{~h}$ at $40{ }^{\circ} \mathrm{C}$. Subsequently gels were stained for $30 \mathrm{~min}$ at $20^{\circ} \mathrm{C}$ in $0.15 \%$ Congo Red and destained overnight in $1 \mathrm{M}-\mathrm{NaCl}\left(4^{\circ} \mathrm{C}\right)$. To improve the resolution for photography, gels were submerged in $5 \%(\mathrm{v} / \mathrm{v})$ acetic acid whereby the colour changed from red to purple.

For activity staining of $\beta$-glucosidase activity the gels were washed as described above. Subsequently Whatman no. 1 filter paper saturated with $5 \mathrm{mM}$-methylumbelliferyl- $\beta$-glucoside (MUG) in $0.1 \mathrm{M}$-phosphate-citrate buffer ( $\mathrm{pH} \mathrm{6.0)}$ was overlaid on the gels and these were incubated for $30 \mathrm{~min}$ at $40^{\circ} \mathrm{C}$. Positive bands were detected by fluorescence under UV illumination (long wavelength).

Protein assay. The protein concentrations of culture filtrates were assayed with Bio-Rad protein reagent with bovine $\gamma$-globulin as a standard (Bio-Rad). 


\section{Results}

\section{Growth of Piromyces strain E2 on different substrates}

The ability of Piromyces strain E2 to use a range of carbon sources in defined medium M2 was investigated. Growth occurred on bagasse, cellobiose, filter paper cellulose, fructose, glucose, lactose, mannose, soluble starch, wheat bran, wheat straw, xylan and xylose but not on arabinose, galactose, inulin, raffinose, ribose and sucrose. The period in which growth occurred (determined by $\mathrm{H}_{2}$ production) varied from $96 \mathrm{~h}$ (cellobiose and filter paper cellulose) to $164 \mathrm{~h}$ (lactose). Measurement of residual reducing sugar confirmed that all monoand disaccharides, except lactose, were used completely. The reducing sugar remaining $(48 \%)$ after growth of the fungus on lactose was probably galactose as the fungus was unable to utilize this monosaccharide. Soluble starch and xylan were digested almost completely as only small amounts of reducing sugars $(<2 \%$ of the substrate added) were formed after acid hydrolysis at room temperature with $67 \% \mathrm{H}_{2} \mathrm{SO}_{4}$. Microscopic examination revealed that filter paper cellulose was digested completely.

The amount of carbon in fermentation products after growth on different substrates was calculated (Table 1). For all substrates which were completely used by Piromyces strain E2 an average of $88.5 \mathrm{~mm}$ C-equivalents was recovered in the fermentation products. This is $59 \%$ of the total carbon offered as substrate. For lactosegrown cultures $43.2 \mathrm{~mm}$-carbon was found in the fermentation products. The total carbon in fermentation products of cultures grown on complex substrates (bagasse, wheat bran and wheat straw) was approximately $60 \%$ of that detectable in the fermentation products of cultures grown on completely digested substrates, indicating that the digestion of complex substrates was approximately $60 \%$.

\section{Fermentation products}

Growth of Piromyces strain E2 on different carbohydrate substrates resulted in a mixed type of fermentation with formate, acetate, lactate, ethanol and hydrogen as endproducts (Table 1). The production of malate and succinate was not monitored as these were only minor fermentation products ( $<2 \mathrm{mM}$; Teunissen et al., 1991 b). No $\mathrm{C}_{3}-\mathrm{C}_{6}$ volatile fatty acids or $\mathrm{C}_{1}-\mathrm{C}_{5}$ alcohols other than ethanol could be detected.

Formate and acetate were the major products of all fermentations. Relatively high amounts of lactate were found in cultures with mannose, xylan and xylose as substrates, whereas in lactose and wheat straw grown cultures lactate production was relatively low. Ethanol production was highest in filter paper and starch grown cultures. Hydrogen production was relatively high after growth on the complex substrates.

\section{Enzyme production}

The effect of growth substrate on cellulase and xylanase production by Piromyces strain E2, was examined (Table 2). The activities of the cellulolytic enzymes were highest in cultures grown on fructose, filter paper cellulose,

Table 1. Fermentation products after growth of Piromyces strain E2 on different substrates

Each value represents the mean \pm SD $(n=4)$.

\begin{tabular}{|c|c|c|c|c|c|c|}
\hline Substrate & $\begin{array}{l}\text { Acetate } \\
\text { (mM) }\end{array}$ & $\begin{array}{c}\text { Ethanol } \\
(\mathrm{mM})\end{array}$ & $\begin{array}{l}\text { Formate } \\
(\mathrm{mM})\end{array}$ & $\begin{array}{l}\text { Hydrogen* } \\
(\mathrm{mm})\end{array}$ & $\begin{array}{c}\text { Lactate } \\
(\mathrm{mM})\end{array}$ & $\begin{array}{l}\text { Total } \mathrm{C} \dagger \\
\text { (mM) }\end{array}$ \\
\hline \multicolumn{7}{|c|}{ Soluble substrates } \\
\hline Cellobiose & $15 \cdot 2 \pm 0 \cdot 1$ & $6 \cdot 1 \pm 0 \cdot 6$ & $32 \cdot 2 \pm 3 \cdot 4$ & $6 \cdot 6 \pm 1 \cdot 0$ & $5 \cdot 7 \pm 1 \cdot 0$ & $91 \cdot 9 \pm 4 \cdot 2$ \\
\hline Fructose & $16 \cdot 4 \pm 0.4$ & $5.4 \pm 0.6$ & $33.4 \pm 1.8$ & $10.9 \pm 0.6$ & $3 \cdot 3 \pm 0.4$ & $86.9 \pm 6.9$ \\
\hline Glucose & $13.4 \pm 0.3$ & $5 \cdot 4 \pm 0 \cdot 2$ & $29 \cdot 3 \pm 2 \cdot 1$ & $4 \cdot 8 \pm 0.5$ & $5 \cdot 6 \pm 0 \cdot 4$ & $83.9 \pm 3.9$ \\
\hline Lactose & $9.9 \pm 0.8$ & $1.8 \pm 0.4$ & $17.5 \pm 1.5$ & $13.0 \pm 2.0$ & $0.7 \pm 0.1$ & $43 \cdot 2 \pm 3 \cdot 4$ \\
\hline Mannose & $13 \cdot 0 \pm 0.3$ & $5.4 \pm 0.6$ & $22 \cdot 2 \pm 1.5$ & $6.0 \pm 0.5$ & $8 \cdot 6 \pm 1 \cdot 2$ & $84 \cdot 7 \pm 5 \cdot 8$ \\
\hline Xylose & $13 \cdot 3 \pm 0.8$ & $6 \cdot 4 \pm 0.3$ & $23.5 \pm 0.4$ & $6 \cdot 0 \pm 0.2$ & $9 \cdot 4 \pm 1 \cdot 8$ & $91.0 \pm 2.8$ \\
\hline \multicolumn{7}{|c|}{ Insoluble substrates } \\
\hline Bagasse & $11 \cdot 0 \pm 0 \cdot 3$ & $2 \cdot 3 \pm 0.2$ & $16 \cdot 2 \pm 2 \cdot 9$ & $9 \cdot 0 \pm 2 \cdot 7$ & $2 \cdot 1 \pm 0 \cdot 2$ & $49 \cdot 1 \pm 4 \cdot 2$ \\
\hline Filter paper & $14.4 \pm 0.9$ & $8 \cdot 6 \pm 0.6$ & $28 \cdot 7 \pm 2 \cdot 6$ & $8 \cdot 7 \pm 0 \cdot 1$ & $4.6 \pm 0.6$ & $88 \cdot 3 \pm 6 \cdot 1$ \\
\hline Starch & $15 \cdot 8 \pm 1 \cdot 3$ & $8.6 \pm 0.7$ & $29 \cdot 7 \pm 2 \cdot 2$ & $7 \cdot 7 \pm 0.3$ & $4.8 \pm 1.4$ & $92.8 \pm 9.6$ \\
\hline Wheat bran & $10 \cdot 1 \pm 0.6$ & $4 \cdot 1 \pm 0.5$ & $15 \cdot 2 \pm 1.6$ & $6.3 \pm 0.6$ & $3.4 \pm 0.8$ & $51 \cdot 3 \pm 4 \cdot 6$ \\
\hline Wheat straw & $11.5 \pm 0.3$ & $3.2 \pm 0.3$ & $18.4 \pm 1.0$ & $10 \cdot 4 \pm 1 \cdot 0$ & $1.6 \pm 0.3$ & $52 \cdot 5 \pm 1 \cdot 3$ \\
\hline Xylan & $13.4 \pm 0.8$ & $5 \cdot 8 \pm 1.0$ & $22.6 \pm 0.9$ & $7 \cdot 6 \pm 0.7$ & $7 \cdot 2 \pm 0.9$ & $82.6 \pm 7.6$ \\
\hline
\end{tabular}

* Hydrogen was measured in the headspace and normalized to the volume of liquid in the culture bottles.

$\uparrow$ Total $\mathrm{C}$ is total carbon in fermentation products and calculated as follows: $(2 \times$ acetate $)+(2 \times$ ethanol $)$ $+(3 \times$ lactate $)+$ formate. 
Table 2. Enzyme production by Piromyces strain E2 after growth on different substrates

Each value represents the mean \pm SD $(n=4)$.

\begin{tabular}{|c|c|c|c|c|c|}
\hline Substrate & $\begin{array}{c}\text { Avicelase } \\
\left(\mathrm{mIU} \mathrm{ml^{-1 }}\right)\end{array}$ & $\begin{array}{c}\beta \text {-Glucosidase } \\
\left(\mathrm{mIU} \mathrm{ml} \mathrm{m}^{-1}\right)\end{array}$ & $\begin{array}{l}\text { CMCase } \\
\left(\mathrm{IU} \mathrm{ml}^{-1}\right)\end{array}$ & $\begin{array}{l}\text { Xylanase } \\
\left(\text { IU ml } l^{-1}\right)\end{array}$ & $\begin{array}{l}\text { Protein } \\
\left(\mathrm{mg} \mathrm{ml}^{-1}\right)\end{array}$ \\
\hline \multicolumn{6}{|c|}{ Soluble substrates } \\
\hline Cellobiose & $15+1$ & $60+6$ & $0.54+0.04$ & $4.99+0.15$ & $0.134+0.011$ \\
\hline Fructose & $20 \pm 3$ & $77 \pm 7$ & $0.96 \pm 0.14$ & $6.47 \pm 0.27$ & $0.121 \pm 0.004$ \\
\hline Glucose & $7 \pm 1$ & $40 \pm 3$ & $0.45 \pm 0.05$ & $3.37 \pm 0.59$ & $0 \cdot 130 \pm 0.003$ \\
\hline Lactose & $39 \pm 6$ & $61 \pm 6$ & $0.84 \pm 0.11$ & $6.44 \pm 0.47$ & $0.078 \pm 0.009$ \\
\hline Mannose & $10 \pm 2$ & $49 \pm 6$ & $1.88 \pm 0.19$ & $4.96 \pm 0.50$ & $0.170 \pm 0.003$ \\
\hline Xylose & $9 \pm 1$ & $37 \pm 3$ & $0.77 \pm 0.16$ & $7 \cdot 96 \pm 0.37$ & $0.146 \pm 0.010$ \\
\hline \multicolumn{6}{|c|}{ Insoluble substrates } \\
\hline Bagasse & $4 \pm 1$ & $13 \pm 2$ & $0.30 \pm 0.06$ & $6.08 \pm 0.22$ & $0.139 \pm 0.009$ \\
\hline Filter Paper & $23 \pm 3$ & $64 \pm 3$ & $1.33 \pm 0.07$ & $8.05 \pm 0.15$ & $0.136 \pm 0.007$ \\
\hline Starch & $23 \pm 3$ & $58 \pm 18$ & $0.96 \pm 0.23$ & $7.02 \pm 0.27$ & $0.168 \pm 0.021$ \\
\hline Wheat bran & $6 \pm 1$ & $16 \pm 9$ & $0.30 \pm 0.04$ & $7.65 \pm 0.32$ & $0.168 \pm 0.013$ \\
\hline Wheat straw & $3 \pm 1$ & $27 \pm 8$ & $0.33 \pm 0.06$ & $7 \cdot 29 \pm 0.32$ & $0.268 \pm 0.017$ \\
\hline Xylan & $15 \pm 1$ & $24 \pm 3$ & $0.62 \pm 0.25$ & $4 \cdot 81 \pm 0.60$ & $0.150 \pm 0.017$ \\
\hline
\end{tabular}

lactose, and starch. Although, cellulose was expected to be best inducer of all cellulolytic enzymes, avicelase, $\beta$-glucosidase and CMCase activities were significantly higher in cultures grown on lactose, fructose and mannose, respectively, than in cultures grown on filter paper cellulose. Xylanase activity was high in cultures grown on filter paper, starch, wheat straw, wheat bran and xylose.

Although the amount of protein secreted was relatively constant (Table 2), extracellular protein was higher in wheat-straw-grown cultures and reduced in lactose grown cultures. The highest specific activities for avicelase, $\beta$-glucosidase and xylanase were found in the lactose-grown cultures $[0.5,0.78$ and $82.6 \mathrm{IU}(\mathrm{mg}$ protein $)^{-1}$, respectively], whereas the highest specific activity for endoglucanase $\left(11 \cdot 1 \mathrm{IU} \mathrm{mg}^{-1}\right)$ was found in the mannose-grown culture.

\section{Protein and enzyme activity patterns after SDS-PAGE}

Most micro-organisms produce isoenzymes. Differences in enzyme activities obtained after growth on the different substrates could therefore be the result of variations in isoenzymes synthesized. The influence of growth substrate on the synthesis of enzymes with $\beta$-glucosidase or endoglucanase activity was examined by SDS-PAGE.

The protein banding patterns for samples obtained after growth of Piromyces strain E2 on different substrates are shown in Fig. 1. Relatively faint patterns were obtained with protein samples from cultures grown on bagasse, wheat straw and wheat bran although twice as much protein was applied to the gels compared to samples obtained from cultures grown on the other substrates. Protein banding patterns were quite similar and only slight differences were observed. Compared to samples from cultures grown on starch, fructose, cellobiose, glucose, mannose and xylose the $44 \mathrm{kDa}$ protein is less pronounced in samples from filter paper and xylangrown cultures (band 1). Protein band 2 is only clearly visible in the sample from the starch-grown culture, whereas protein band 3 is pronounced in samples from cultures grown on xylan, fructose, cellobiose, glucose, mannose and xylose.

The endoglucanase activity patterns for samples obtained after growth of Piromyces strain E2 on the different substrates are shown in Fig. 2. Endoglucanase activity bands resulted in clear hydrolysis zones against a dark background. A dark band that formed within some of the clearing zones during destaining was probably due to the presence of an acid protein or the formation of an acid product by the enzymes. Isoenzymes having molecular masses of $215,150,128,110$ and $55 \mathrm{kDa}$ were detected in all enzyme preparations. The enzyme preparation obtained after growth on lactose contained extra endoglucanase activity bands with molecular masses between 120 and $200 \mathrm{kDa}$.

The $\beta$-glucosidase activity patterns for samples obtained after growth of Piromyces strain E2 on the different substrates are shown in Fig. 3. Most distinct $\beta$ glucosidase activity patterns were detected for filterpaper and lactose-grown cultures. The most distinct $\beta$ glucosidase activity band had a molecular mass of $110 \mathrm{kDa}$; fainter $\beta$-glucosidase bands having molecular masses of $81,67,60$ and $46 \mathrm{kDa}$ were also detected. No significant differences in $\beta$-glucosidase activity patterns were found for the enzyme samples from other cultures. 


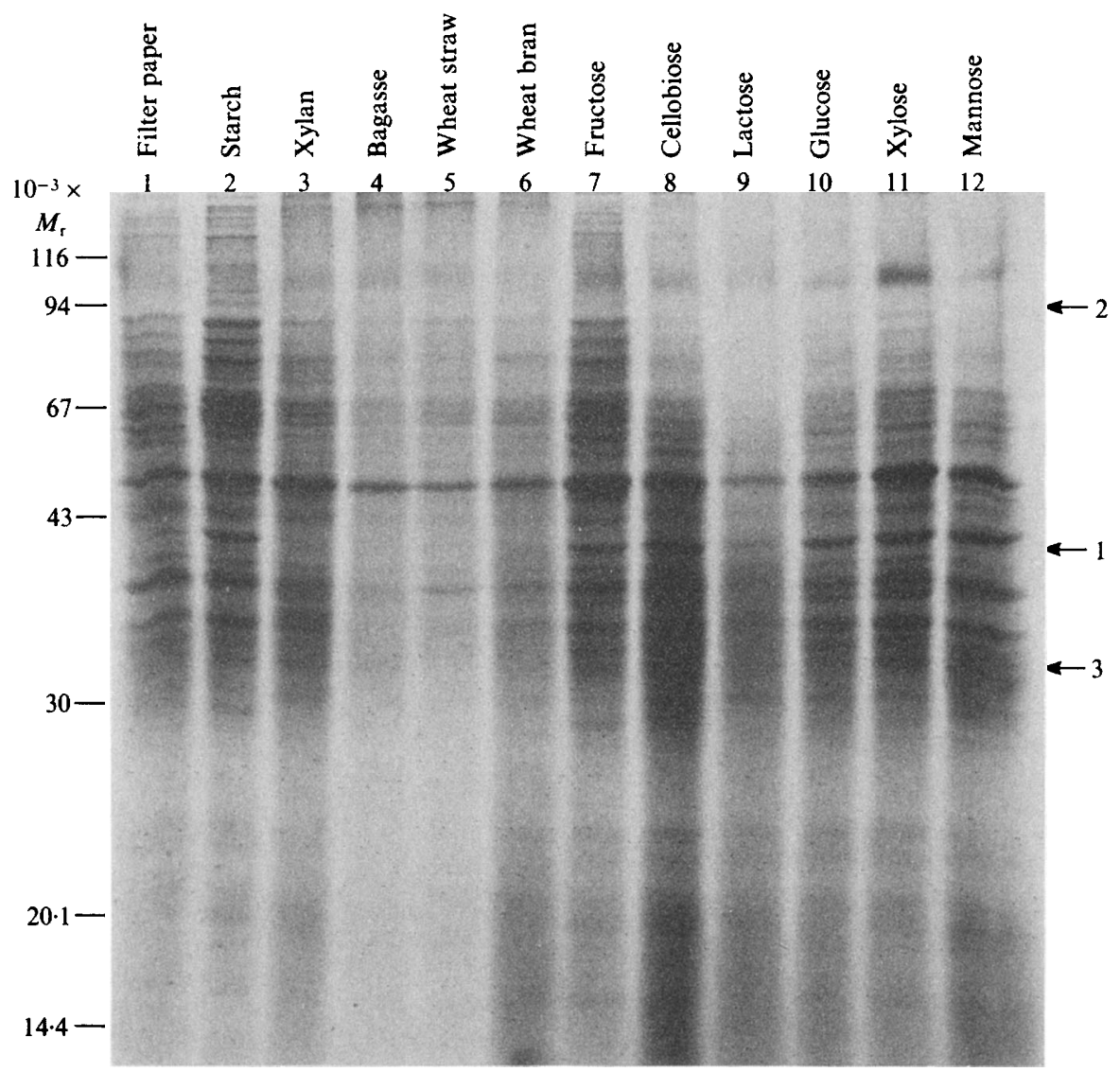

Fig. 1. Protein banding pattern of extracellular proteins from Piromyces strain E2 grown on several substrates. The amount of protein applied to lanes 1-3 and 7-12 was $25 \mu \mathrm{g}$. To lanes 4-6, $50 \mu \mathrm{g}$ protein was applied. Migration was from top to bottom. The positions of molecular mass markers are indicated. Arrows on the right indicate specific protein bands (see Results).

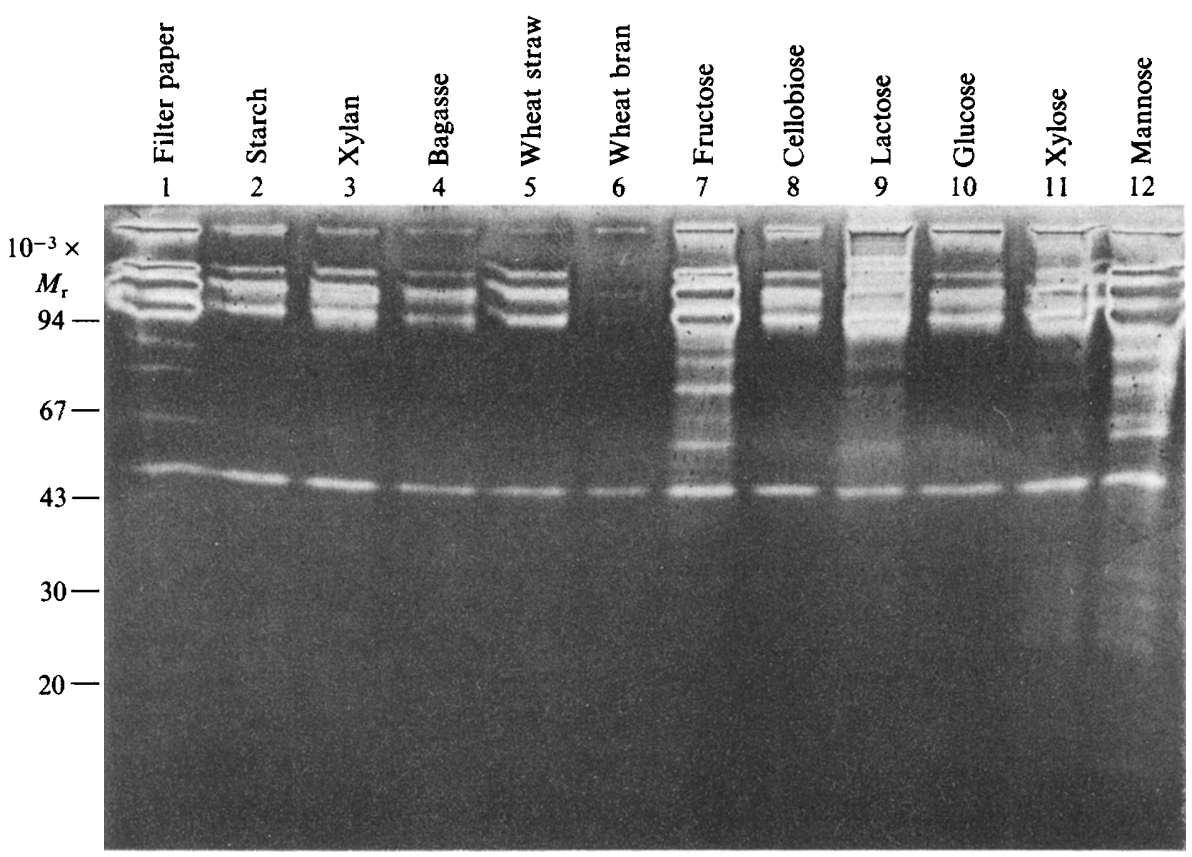

Fig. 2. Endoglucanase activity banding patterns of extracellular enzymes from Piromyces strain E2 grown on several substrates. The amount of protein applied to lanes $1-3$ and 7-12 was $5 \mu \mathrm{g}$. To lanes 4-6, $10 \mu \mathrm{g}$ protein was applied. Migration was from top to bottom. The positions of molecular mass markers are indicated. 


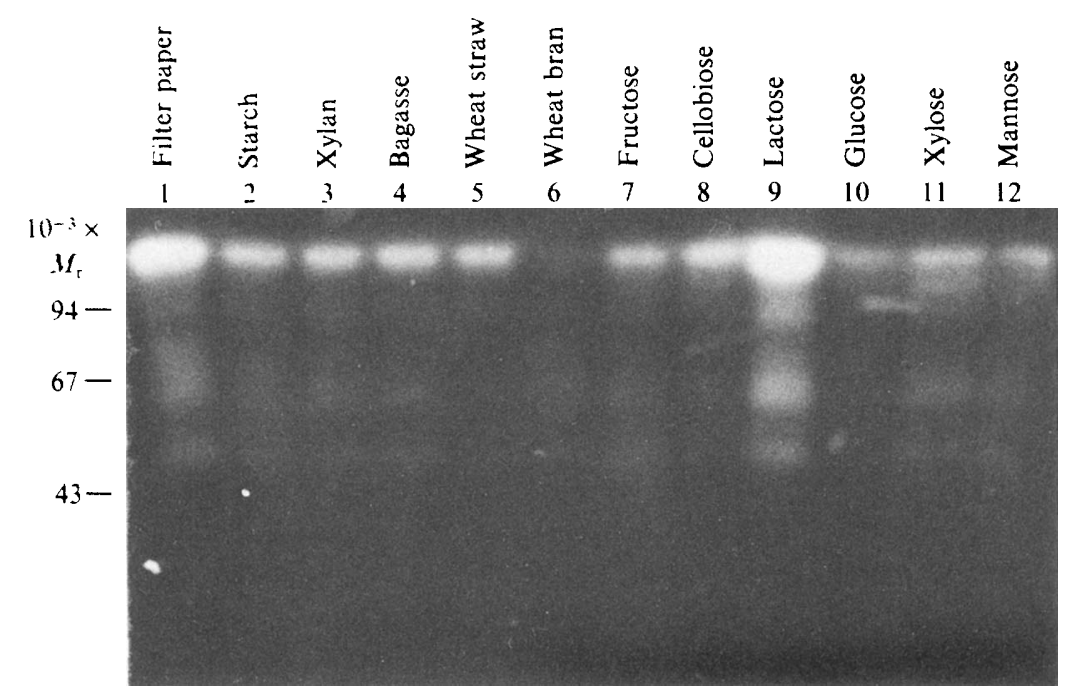

Fig. 3. $\beta$-Glucosidase activity banding patterns of extracellular proteins from Piromyces strain E2 grown on several substrates. The amount of protein applied to lanes 1-3 and 7-12 was $25 \mu \mathrm{g}$. To lanes 4-6, 50 $\mu \mathrm{g}$ protein was applied. Migration was from top to bottom. The positions of molecular mass markers are indicated.

\section{Discussion}

Anaerobic fungi, isolated from ruminants, produce high levels of cellulolytic and xylanolytic enzymes when grown on a range of substrates (Mountfort \& Asher, 1985; Lowe et al., 1987b; Williams \& Orpin, 1987a, b). However, the ability of anaerobic fungi from nonruminants to utilize different carbohydrates, and the effects of these substrates on enzyme formation have not been described. Piromyces strain E2 isolated from an Indian elephant, a non-ruminant, has been shown to produce high levels of cellulolytic and xylanolytic enzymes after growth on filter paper cellulose (Teunissen et al., 1991 b). The results presented here confirmed that this fungus was able to use a range of substrates which in turn had effects on fermentation pattern and production of cellulolytic and xylanolytic enzymes.

Piromyces strain E2 did not grow on galactose, inulin, sucrose and raffinose. The eight ruminal Piromyces species tested by Phillips \& Gordon (1988) likewise did not grow on inulin but the ability to ferment sucrose and inulin was shown to be strain dependent. These Piromyces species have not been tested for their ability to utilize galactose. Neocallimastix patriciarum utilized galactose (Orpin \& Bountiff, 1978) whereas two other ruminal Neocallimastix spp. (Mountfort \& Asher, 1985; Lowe et al., 1987a) did not grow on this substrate. Piromyces strain E2 is the first anaerobic fungus shown to be able to ferment mannose; none of the ruminal Neocallimastix, Caecomyces and Piromyces species tested were able to ferment this carbohydrate (Lowe et al., $1987 a$; Phillips \& Gordon, 1988).
Formate was the major endproduct on all substrates and the molar ratio of soluble fermentation products after growth of Piromyces strain E2 was not substrate dependent. The production of hydrogen was more variable. The anaerobic rumen fungus Neocallimastix frontalis was shown to convert carbohydrates via glycolysis to pyruvate which was then decarboxylated or reduced to lactate. No evidence was found for carbohydrate metabolism via the tricarboxylic acid cycle or the pentose phosphate pathway (O'Fallon et al., 1991). The intermediary metabolism of carbohydrates in Piromyces strain E2 would appear similarly restricted in view of the relatively constant ratio of fermentation products formed. There is little known about the influence of growth substrate on fermentation pattern. Growth of Neocallimastix strain $\mathrm{N} 1$ on xylose instead of glucose resulted in increased production of acetate, carbon dioxide and hydrogen, whereas the production of lactate was lower (Lowe et al., 1987a). About $60 \%$ of the carbon offered as substrate was recovered as carbon in fermentation products. Similar results were obtained for ruminal Neocallimastix strains and non-ruminal Piromyces strains grown on filter paper cellulose (Teunissen et al., 1991 b).

Cellulolytic and xylanolytic enzymes were produced by Piromyces strain E2 after growth on monosaccharide, disaccharide, polysaccharide or complex carbon sources. Enzyme production was substrate dependent but differences were less pronounced than were found for ruminal Piromyces species (Williams \& Orpin, 1987a, b). Studies with Neocallimastix frontalis (Mountfort \& Asher, 1985) and Neocallimastix patriciarum (Orpin \& Letcher, 1979; Orpin, 1983/1984) indicated that enzyme production was 
substrate dependent and that soluble sugars were less effective inducers of cellulase than cellulose. Furthermore, Mountfort \& Asher (1985) demonstrated that the production of endoglucanase by Neocallimastix frontalis was repressed by glucose and other soluble sugars. Enzyme production was high for cellobiose, lactose, fructose and starch grown cultures. Lactose has been referred to as an inducer of cellulolytic enzymes (Gong $e t$ al., 1979) or a non-repressive carbon source for aerobic fungi (Biely et al., 1980). Cellobiose was found to be an effective inducer of Neocallimastix frontalis cellulases (Mountfort \& Asher, 1985). Similar results were obtained with the aerobic fungus Trichoderma reesei (Mandels \& Reese, 1960) and the actinomycete Sporotrichum pulverulentum (Erikson \& Hamp, 1978). Neither fructose nor starch have been shown before to be inducers of cellulolytic enzymes. Enzyme production during growth on these substrates may be high because of the absence of repression. Complex substrates were not inducers of cellulolytic enzymes, and enzyme production was 3-4times lower.

Xylanase production was not repressed by xylose. Both repression (Richards \& Shambe, 1976) and induction (Kluepfel et al., 1990) of xylanase synthesis by xylose for an aerobic fungus and an actinomycete, respectively, have been described. After growth on complex substrates and filter paper cellulose, production of xylanolytic enzymes were comparable. It is not clear why after growth on oat spelt xylan, xylanase production was $40 \%$ lower than after growth on filter paper cellulose, as Neocallimastix strain $\mathrm{R} 1$ produced more xylanase during growth on xylan and wheat straw than after growth on microcrystalline cellulose (Avicel) (Lowe et al., 1987b). For the aerobic fungus Trichoderma koningii, crystalline cellulose induced highly active xylanases in addition to all components of the cellulase system (Huang et al., 1991). The mode of regulatory mechanism was not established for Piromyces strain E2 but it was apparent that xylanolytic enzyme production was constitutive, although enzyme activities were lower after growth on glucose and other soluble sugars. Similar results were obtained for ruminal Neocallimastix (Williams \& Orpin, $1987 a$ ) and Piromyces strains (Lowe et al., 1987b; Williams \& Orpin, 1987a; Gordon \& Phillips, 1989).

Little is known of the molecular masses of cellulolytic enzymes of anaerobic fungi. PAGE and activity staining of extracellular enzymes of Neocallimastix frontalis gave multiple bands for endoglucanase activity but molecular details could not be obtained by this technique (Barichiviech \& Calza, 1990). Two $\beta$-glucosidases from the rumen fungus Neocallimastix frontalis have been purified and differed in molecular mass and pI being $120 \mathrm{kDa}$ and 3.85 (Hebraud \& Fevre, 1990), and $125.5 \mathrm{kDa}$ and $7 \cdot 10$ (Li \& Calza, 1991). These molecular masses coincide with one of the distinct activity bands found for the Piromyces strain used in this study. However, the resolution of the SDS-PAGE technique is not high enough to differentiate between these $\beta$-glucosidases.

Samples from Piromyces strain E2 cultured on various substrates gave almost identical $\beta$-glucosidase and endoglucanase activity patterns after SDS-PAGE. This indicates that the differences in enzyme production on different substrates were not caused by secretion of different mixtures of isoenzymes. It is possible that the amount of each isoenzyme produced is influenced by the growth substrate but the intensity of activity bands was similar for all substrates tested. The SDS-PAGE technique used here did not allow absolute quantification of the activity of the isoenzymes. In contrast, PAGE separation of the extracellular endoglucanases of Neocallimastix frontalis confirmed that several activity bands present in cellulose-grown cultures were not present or were less active in cellobiose- and glucose-grown cultures (Barichiviech \& Calza, 1990).

Only minor differences were found in the protein banding patterns of extracellular proteins of Piromyces strain E2 cultured on different substrates, which is indicative of constitutive enzyme production by this anaerobic fungus. For Neocallimastix frontalis the protein banding pattern was found to be substrate dependent (Barichiviech \& Calza, 1990; Calza, 1991). The banding patterns of extracellular proteins of cultures on complex substrates were relatively faint. It is possible that during growth on the complex substrates substances are released (e.g. phenolic acids) which interfere with the protein determination. This would result in an overestimation of protein applied to the gel.

This research was supported by a grant from the Ministry of Economic Affairs of the Netherlands.

\section{References}

Barichiviech, E. M. \& Calza, R. E. (1990). Supernatant protein and cellulase activities of the anaerobic ruminal fungus Neocallimastix frontalis EB188. Applied and Environmental Microbiology 56, 43-48.

BARR, D. J. S., Kudo, H., JAKober, K. \& ChENG, K.-J. (1989) Morphology and development of rumen fungi: Neocallimastix sp., Piromyces communis, and Orpinomyces bovis gen. nov., sp. nov. Canadian Journal of Botany 67, 2815-2824.

Bauchop, T. \& MountForT, D. O. (1981). Cellulose fermentation by a rumen anaerobic fungus in both the absence and presence of rumen methanogens. Applied and Environmental Microbiology 42, 11031110.

Biely, P., Kratky, Z., Vranska, M. \& Urmanicova., D. (1980). Induction and inducers of endo-1,4-xylanase in the yeast Cryptococcus albidus. European Journal of Biochemistry 108, 323-329.

Breton, A., Bernalier, A., Dusser, M., Fonty, G., GaillardMARTINI, B. \& Guillot, J. (1990). Anaeromyces mucronatans nov. gen., nov. sp. A strictly anaerobic rumen fungus with polycentric thallus. FEMS Microbiology Letters 70, 177-182.

CALZA, R. E. (1991). Regulation of protein and cellulase excretion in the ruminal fungus Neocallimastix frontalis EB 188. Current Microbiology 21, 109-115. 
ERIKSON, K. E. \& HAMP, S. G. (1978). Regulation of endo- $\beta-1$,4-Dglucanase production in Sporotrichum pulverulentum. European Journal of Biochemistry 90, 183-190.

GoERING, H. K. \& VAN SOEST, P. J. (1970). Forage Fiber Analyses. Apparatus, Reagents, Procedures and Some Applications. Agricultural Research Service Agricultural Handbook no. 379. Washington DC: US Department of Agriculture.

Gold, J. J., Heath, l. B. \& Bauchop, T. (1988). Ultrastructural description of a new chytrid genus of caecum anaerobe, Caecomyces equi gen. nov., sp. nov,, assigned to the Neocallimasticaceae. BioSystems 21, 403-415.

Gong, C. S., Ladisch, M. R. \& TsaO, G. T. (1979). Biosynthesis, purification and mode of action of cellulases of Trichoderma viride. Advances in Chemistry Series 181, 261-287.

Gordon, G. L. R. \& PhIllips, M. W. (1989). Degradation and utilization of cellulose and straw by three different anaerobic fungi from the ovine rumen. Applied and Environmental Microbiology 55, $1703-1710$.

Hebraud, M. \& FeVre, M. (1990). Purification and characterization of a aspecific glycoside hydrolase from the anaerobic ruminal fungus Neocallimastix frontalis. Applied and Environmental Microbiology 56, 3164-3169.

Ho, Y. W., Abdullah, N. \& Jalaludin, S. (1990). Ruminomyces elegans gen. et spec. nov., a polycentric rumen fungus from cattle. Mycotaxon 38, 397-405.

Huang, L., Hseu, T.-H. \& Wey, T.-T. (1991). Purification and characterization of an endoxylanase from Trichoderma koningii G-39. Biochemical Journal 278, 329-333.

KaWAMORI, M., Morikawa, Y., Ado, Y. \& Takasawa, S. (1986). Production of cellulases from alkali-treated bagasse in Trichoderma reesei. Applied Microbiology and Technology 24, 454-458.

Kluepfel, D., Vats-Mehta, S., Aumont, F., Sharbeck, F. \& Morosoli, R. (1990). Production and characterization of a new xylanase (xylanase B) produced by Streptomyces lividans 66 . Biochemical Journal 267, 45-50.

LAEMMLI, U. K. (1970). Cleavage of structural proteins during the assembly of the head of bacteriophage T4. Nature, London 227, 680685 .

LI, X. \& CALZA, R. E. (1991). Purification and characterization of an extracellular $\beta$-glucosidase from the rumen fungus Neocallimastix frontalis EB188. Enzyme Microbiology and Technology 13, 622-628.

Lowe, S. E., Theodorou, M. K. \& TrincI, A. P. J. (1987a). Growth and fermentation of an anaerobic rumen fungus on various carbon sources and effect of temperature on development. Applied and Environmental Microbiology 53, 1210-1215.

Lowe, S. E., Theodorou, M. K. \& TrincI, A. P. J. (1987b). Cellulases and xylanase of an anaerobic rumen fungus grown on wheat straw, wheat straw holocellulose, cellulose, and xylan. Applied and Environmental Microbiology 53, 1216-1223.

MANDELS, M. \& REESE, E. T. (1960). Induction of cellulase in fungi by cellobiose. Journal of Bacteriology 79, 816-826.

Miller, G. L. (1959). Use of dinitrosalicylic as reagent for the determination of reducing sugars. Analytical Chemistry 31, 426-428

Mountfort, D. O. \& Asher, R. A. (1985). Production and regulation of cellulase by two strains of the rumen anaerobic fungus
Neocallimastix frontalis. Applied and Environmental Microbiology 49, 1314-1322.

O'Fallon, J. V., Wright, R. W., JR \& Calza, R. E. (1991). Glucose metabolic pathways in the anaerobic rumen fungus Neocallimastix frontalis. Biochemical Journal 224, 595-599.

ORPIN, C. G. (1983/1984). The role of ciliate protozoa and fungi in the rumen digestion of plant cell walls. Animal Feed Science and Technology 10, 121-143.

ORPIN, C. G. (1988). Nutrition and biochemistry of anaerobic Chytridiomycetes. BioSystems 21, 365-370.

Orpin, C. G. \& BounTIFF, L. (1978). Zoospore chemotaxis in the rumen phycomycete Neocallimastix frontalis. Journal of General Microbiology 104, 113-122.

ORPIN, C. G. \& LeTCHER, A. J. (1979). Utilization of cellulose, starch, xylan, and other hemicelluloses for growth by the rumen phycomycete Neocallimastix frontalis. Current Microbiology 3, 121-124.

PhILlips, M. W. \& GoRdon, G. L. R. (1988). Sugar and polysaccharide fermentation by rumen anaerobic fungi from Australia, Britain and New Zealand. BioSystems 21, 377-383.

Richards, G. N. \& SHAMBE, T. (1976). Production and purification of two hemicellulases from Cephalosporium sacchari. Carbohydrate Research 49, 371-391.

Schwartz, W. H., Bronnenmeier, K., Gräbnitz, F. \& StaudenBAUER, W. L. (1987). Activity staining of cellulases in polyacrylamide gels containing mixed linkage $\beta$-glucans. Analytical Biochemistry $164,72-77$.

SLEAT, R. \& MAH, R. A. (1984). Quantitative method for colorimetric determination of formate in fermentation media. Applied and Environmental Microbiology 47, 884-885.

Teunissen, M. J., Marras, S. A. E., Op den Camp, H. J. M. \& Vogels, G. D. (1989). An improved method for the quantification of alcohols, volatile fatty acids, and lactate or 2,3-butanediol in biological samples. Journal of Microbiological Methods 10, 247-254.

Teunissen, M. J., Op Den CAMp, H. J. M., ORPIN, C. G., Huis in 'T VELD, J. H. J. \& VoGels, G. D. (1991a). Comparison of growth characteristics of anaerobic fungi isolated from ruminant and nonruminant herbivores during cultivation in a defined medium. Journal of General Microbiology 137, 1401-1408.

Teunissen, M. J., Smits, A. A. M., Op den CAMP, H. J. M., Huis In 'T VELD, J. H. J. \& VoGELS, G. D. (1991 $b$ ). Fermentation of cellulose and production of cellulolytic and xylanolytic enzymes by anaerobic fungi from ruminant and non-ruminant herbivores. Archives of Microbiology 156, 290-296.

Williams, A. G. \& OrPin, C. G. (1987a). Polysaccharide-degrading enzymes formed by anaerobic rumen fungi grown on a range of carbohydrate substrates. Canadian Journal of Microbiology 33, 418426.

Williams, A. G. \& Orpin, C. G. (1987b). Glycoside hydrolase enzymes present in the zoospore and vegetative growth stages of the rumen fungi, Neocallimastix patriciarum, Piromonas communis, and an unidentified isolate, grown on a range of carbohydrates. Canadian Journal of Microbiology 33, 427-434.

Wood, T. M., Wilson, C. A., MCCrae, S. I. \& Joblin, K. N. (1986). A highly active extracellular cellulase from the anaerobic fungus Neocallimastix frontalis. FEMS Microbiology Letters 34, 37-40. 